\title{
QUALIDADE DE VIDA E FATORES ASSOCIADOS EM PESSOAS VIVENDO COM HIV/AIDS
}

\author{
Juliana da Rocha Cabral ${ }^{1}$, Yasmim Talita de Moraes Ramos², Luciana da Rocha Cabral ${ }^{3}$, \\ Danielle Chianca de Andrade Moraes ${ }^{4}$, Magaly Bushatsky ${ }^{5}$, Regina Celia de Oliveira.
}

\begin{abstract}
RESUMO: Objetivo: avaliar a qualidade de vida de pessoas vivendo com o vírus da imunodeficiência humana/Síndrome da imunodeficiência adquirida. Método: estudo transversal, descritivo, quantitativo, realizado com 150 indivíduos cadastrados em um serviço de assistência especializada em Pernambuco, Brasil, entre os meses de fevereiro e agosto de 2016. Para a análise dos dados, utilizou-se dos testes Kolmogorov-Smirnov, Friedman, Mann-Whitney e KruskalWallis. Resultados: sexo e renda familiar foram mais influentes na alteração da qualidade de vida, e o domínio com maior quantitativo de fatores influenciáveis na mensuração desta variável foi a espiritualidade. Conclusão: conclui-se que a qualidade de vida de pessoas vivendo com o vírus da imunodeficiência humana/Síndrome da imunodeficiência adquirida mostra-se prejudicada. Compreender a qualidade de vida como forma de percepção da existência humana, nas esferas objetivas e subjetivas, torna-se essencial, visto que viver com o vírus afeta os indivíduos em todas as áreas da vida.
\end{abstract}

DESCRITORES: Qualidade de vida; vírus da imunodeficiência humana; Síndrome da imunodeficiência adquirida; Saúde; Epidemiologia.

\section{QUALITY OF LIFE AND FACTORS ASSOCIATED WITH PEOPLE LIVING WITH HIV/AIDS}

ABSTRACT: Objective: to evaluate the quality of life of people living with the human immunodeficiency virus/Acquired immunodeficiency syndrome. Method: a descriptive, quantitative, cross-sectional study with 150 individuals enrolled in a specialized care service in Pernambuco, Brazil, between February and August 2016. Data were analyzed using the Kolmogorov-Smirnov, Friedman, Mann-Whitney and Kruskal-Wallis tests. Results: gender and family income were more influential on the quality of life, with the spirituality domain having the greatest number of influential factors in the measurement of this variable. Conclusion: it was concluded that the quality of life of people living with the human immunodeficiency virus/Acquired immunodeficiency syndrome is impaired. Comprehending the quality of life as a form of perception of human existence, in the objective and subjective contexts, becomes essential, as living with the virus affects individuals in all areas of life.

KEYWORDS: Quality of life; human immunodeficiency virus; Acquired immunodeficiency syndrome; Health; Epidemiology.

\section{CALIDAD DE VIDA Y FACTORES ASOCIADOS EN PERSONAS QUE VIVEN CON HIV/SIDA}

RESUMEN: Objetivo: evaluar la calidad de vida de personas con el virus de la inmunodeficiencia humana/Síndrome de la inmunodeficiencia adquirida. Método: estudio transversal, descriptivo, cuantitativo, realizado con 150 individuos registrados en un servicio de asistencia especializada en Pernambuco, Brasil, entre los meses de febrero y agosto de 2016. Para el análisis de los datos, se utilizaron los tests Kolmogorov-Smirnov, Friedman, Mann-Whitney y Kruskal-Wallis. Resultados: sexo y renta familiar fueron más influentes en la alteración de la calidad de vida, y el dominio con mayor cuantitativo de factores influenciables en la mensuración de esa variable fue la espiritualidad. Conclusión: se concluye que la calidad de vida de personas que viven con el virus de la inmunodeficiencia humana/Síndrome de la inmunodeficiencia adquirida se muestra agravioso. Comprender la cualidad de vida como forma de percepción de la existencia humana, en las esferas objetivas y subjetivas, es esencial, ya que vivir con el virus afecta a los individuos en todas las áreas de la vida.

DESCRITORES: Calidad de vida; virus de la inmunodeficiencia humana; Síndrome de la inmunodeficiencia adquirida; Salud; Epidemiología.

${ }^{1}$ Enfermeira. Mestranda em Enfermagem pelo Programa de Pós-graduação da Universidade de Pernambuco/Universidade Estadual da Paraíba. Recife, Pernambuco, Brasil.

${ }^{2}$ Acadêmica do Curso de Enfermagem da Faculdade de Enfermagem Nossa Senhora das Graças da Universidade de Pernambuco. Recife, Pernambuco, Brasil.

${ }^{3}$ Enfermeira. Pós-graduanda em Saúde da Mulher pelo Programa de Residência em Enfermagem. Recife, Pernambuco, Brasil.

4Enfermeira. Doutoranda em Enfermagem pelo Programa de Pós-graduação da Universidade de Pernambuco/Universidade Estadual da Paraíba. Recife, Pernambuco, Brasil.

${ }^{5}$ Enfermeira. Doutora em Saúde da Criança e do Adolescente. Professora da Faculdade de Enfermagem Nossa Senhora das Graças da Universidade de Pernambuco. Recife, Pernambuco, Brasil.

${ }^{6}$ Enfermeira. Doutora em Enfermagem. Professora da Faculdade de Enfermagem Nossa Senhora das Graças da Universidade de Pernambuco. Recife, Pernambuco, Brasil.

R. Brasilândia, no 23, CEP: 50720-730, Recife, Pernambuco, Brasil.

E-mail: jucabral06@hotmail.com 


\section{INTRODUÇÃO}

A infecção pelo vírus da imunodeficiência humana (HIV), causador a Síndrome da Imunodeficiência Adquirida (Aids), representa um dos maiores problemas de saúde pública no mundo. O relatório publicado pelo Programa Conjunto das Nações Unidas sobre HIV/Aids (UNAIDS) revelou que no final do ano de 2015 aproximadamente 36,7 milhões de pessoas viviam com o HIV no mundo ${ }^{(1)}$. No Brasil, as estimativas apontaram que desde o início da epidemia até 2016 foram registradas mais de 842 mil pessoas infectadas pelo vírus ${ }^{(2)}$.

Em razão da magnitude epidemiológica do HIV, o governo federal brasileiro estabeleceu, na década de 1990, a criação de uma rede de serviços integrada ao Sistema Único de Saúde (SUS) direcionada para o diagnóstico, aconselhamento e tratamento dessa infecção. Além disso, o governo, em estreita articulação com redes de movimentos sociais e organizações não governamentais (ONGs), garantiu a distribuição gratuita da Terapia Antirretroviral (TARV) necessária ao tratamento, sendo possível alcançar um aumento significativo na sobrevida e na qualidade de vida (QV) das pessoas vivendo com HIV/Aids $(\mathrm{PVAH})^{(3)}$.

Nesse contexto, mensurar a QV de PVHA é essencial, uma vez que a descoberta do diagnóstico de uma doença transmissível, incurável até o momento, de caráter estigmatizante e com consequências biopsicosocioculturais, repercute negativamente na vida dos sujeitos ${ }^{(4)}$. Assim, a literatura afirma que a QV possui significados individuais, considerados um construto cultural que precisa, constantemente, ser discutido e transformado de acordo com fatores relevantes, como os aspectos históricos, socioculturais, psíquicos, ambientais e da inserção no mundo do trabalho ${ }^{(5)}$.

Ainda nessa dimensão, cabe destacar que a QV tem sido utilizada como parâmetro de avaliação em saúde, pois permite a compreensão mais ampla dos prejuízos causados pela infecção, por meio da atenção individualizada e direcionada para a subjetividade de cada sujeito, sendo, dessa maneira, capaz de garantir a percepção das necessidades de saúde das pessoas acometidas pelo vírus e de predizer as adequações ao direcionamento aos serviços de apoio interdisciplinares ${ }^{(6)}$.

Apesar de as tendências globais revelarem um declínio da epidemia do HIV, ainda existe uma parcela significativa da população que continua a enfrentar os prejuízos advindos da confirmação diagnóstica, por conseguinte, a medição da QV é um fator-chave na determinação do prognóstico desses indivíduos ${ }^{(7)}$.

Diante da vulnerabilidade imposta pela infecção pelo HIV, torna-se imprescindível um maior conhecimento a respeito da QV das PVHA, com o intuito de contribuir para o desenvolvimento de novas discussões que visem ao aprimoramento das estratégias no campo das políticas públicas voltadas para a assistência integral à saúde desse grupo. Espera-se, também, contribuir para a identificação dos aspectos que apresentam maior relevância para a manutenção de uma QV satisfatória.

Frente a essas considerações, o objetivo deste estudo foi avaliar a qualidade de vida de pessoas vivendo com HIV/Aids.

\section{MÉTODO}

Estudo descritivo, transversal, com abordagem quantitativa, desenvolvido em um Serviço de Assistência Especializada em HIV/Aids (SAE) do município de Recife, Pernambuco, Brasil.

Para os critérios de elegibilidade, foram incluídas PVHA que possuíam idade igual ou superior a 18 anos e estavam inseridas no Sistema de Controle Logístico de Medicamentos Antirretrovirais (SICLOM), do Ministério da Saúde. Foram excluídos os indivíduos que apresentaram distúrbios/patologias mentais e/ou declínio cognitivo, registrados em prontuário, que afetavam a capacidade perceptiva, de discernimento, de linguagem e que interferissem, portanto, na comunicação do entrevistado e no entendimento das questões referentes à realização da entrevista. 
Para a seleção da amostra, optou-se por utilizar a técnica de amostragem não probabilística, assim, 150 indivíduos compuseram a amostra. A coleta de dados ocorreu entre os meses de fevereiro e agosto de 2016, antes ou após a consulta médica, e foi realizada por meio de entrevistas individuais, em salas do próprio serviço, o que proporcionou privacidade para o entrevistado e o entrevistador.

Para obtenção dos dados referentes às variáveis independentes, foi utilizado questionário estruturado composto de dados socioeconômicos (sexo, idade, escolaridade, estado civil, renda, ocupação), comportamentais de saúde (tempo de diagnóstico e tratamento, atividade física e uso de preservativo) e informações clínicas (forma de contágio do HIV, situação clínica, presença de infecções oportunistas e registro de adesão à TARV em prontuário).

Como a variável dependente foi a QV, optou-se pelo instrumento de avaliação da Qualidade de Vida da Organização Mundial da Saúde de pessoas infectadas pelo HIV, versão abreviada (WHOQOLHIV-Bref), criado e validado pela Organização Mundial de Saúde (OMS). Esse instrumento é composto de 31 questões, divididas em seis domínios: físico, psicológico, relações sociais, ambiente, nível de independência e espiritualidade/religião/crenças pessoais. Ao responder, o indivíduo era orientado a pensar em sua QV nas últimas duas semanas. As respostas têm formato de escala Likert de cinco pontos. Todos os escores refletem linearmente a QV, a pontuação 1 é indicativa de percepção de QV baixa e negativa, e a 5 indica percepção alta e positiva. As facetas formuladas negativamente, como dor e desconforto, sentimentos negativos, dependência de medicação, morte e morrer foram invertidas, conforme documento oficial da OMS, já disponível em português ${ }^{(8)}$.

Os dados foram armazenados no programa Statistical Package for the Social Sciences (SPSS), versão 18.0, para a realização da análise estatística. Foi utilizada análise descritiva para a caracterização socioeconômica, comportamental de saúde e clínica, sendo calculadas as frequências percentuais e construídas as respectivas distribuições de frequência. Média e desvio-padrão foram calculados para a avaliação dos escores dos domínios do WHOQOL-HIV-Bref. A normalidade do escore foi verificada pelo teste Kolmogorov-Smirnov. Nos casos em que não foi indicada normalidade do escore, aplicou-se o teste de Friedman para averiguar a existência de diferença do escore entre os domínios.

Para identificar a relação dos escores de QV com os perfis socioeconômico, comportamental de saúde e clínico, foram aplicados os testes de Mann-Whitney quando os fatores possuíam duas categorias. O teste de Kruskal-Wallis foi utilizado quando os fatores apresentaram mais de duas categorias. Considerouse um nível de significância de 0,05.

O estudo obedeceu à Resolução n. ${ }^{\circ}$ 466/2012 do Conselho Nacional de Saúde, e foi submetido ao Comitê de Ética em Pesquisa do Complexo Hospitalar do HUOC/PROCAPE e aprovado com o parecer 1.112.733.

\section{RESUltADOS}

$\mathrm{Na}$ Tabela 1 constam as frequências relativas e absolutas do perfil sociodemográfico, clínico e comportamental de saúde dos avaliados. Na distribuição socioeconômica dos entrevistados, observase que $98(65,3 \%)$ participantes são do sexo feminino, e que os extremos etários variaram de 18 a 69 anos, com média de 37,21 anos, desvio-padrão de 10,77 anos e mediana de 37,5 anos. Verifica-se que $90(60 \%)$ pesquisados não cursaram o $2^{\circ}$ grau completo, e $74(49,3 \%)$ referiram ser casados ou viver com o companheiro. Quanto à renda familiar, $92(61,3 \%)$ participantes sobreviviam com até um salário mínimo (SM), e 85 (56,7\%) não possuíam vínculo empregatício formal/informal.

No que concerne aos dados relacionados às variáveis comportamentais de saúde e clínicas, verificouse que o tempo médio de descoberta do HIV foi de 6,2 anos e desvio-padrão de 16,51 anos. Já a média de tratamento com a TARV foi de 5,5 anos e desvio-padrão de 7,13 anos.

Dos entrevistados, 125 (83,3\%) relataram não praticar nenhum tipo de atividade física, e 88 (58,7\%) reportaram utilizar preservativos em suas relações sexuais. Das PVHA, 146 (97,3\%) afirmaram que a via de contágio pelo HIV foi por meio da relação sexual. 
No que tange aos dados clínicos, 115 (76,7\%) nunca desenvolveram infecções oportunistas, e 116 $(77,2 \%)$ não apresentaram registro de falta de adesão à TARV em prontuário.

Tabela 1 - Distribuição da frequência absoluta e relativa do perfil sociodemográfico, clínico e comportamental de saúde dos avaliados. Recife, PE, Brasil, 2016. (continua)

\begin{tabular}{|c|c|c|c|}
\hline Fator avaliado & $\mathbf{N}$ & $\%$ & p-valor ${ }^{1}$ \\
\hline \multicolumn{4}{|l|}{ Sexo } \\
\hline Feminino & 98 & 65,3 & \multirow{2}{*}{$<0,001$} \\
\hline Masculino & 52 & 34,7 & \\
\hline \multicolumn{4}{|l|}{ Faixa etária } \\
\hline 18 a 28 & 35 & 23,3 & \multirow{4}{*}{$<0,001$} \\
\hline 29 a 39 & 55 & 36,7 & \\
\hline 40 a 60 & 59 & 39,3 & \\
\hline Maior que 60 & 1 & 0,7 & \\
\hline \multicolumn{4}{|l|}{ Escolaridade } \\
\hline Nenhuma & 3 & 2 & \multirow{7}{*}{$<0,001$} \\
\hline $1^{\circ}$ grau completo & 21 & 14 & \\
\hline $1^{\circ}$ grau incompleto & 44 & 29,3 & \\
\hline $2^{\circ}$ grau completo & 43 & 28,7 & \\
\hline $2^{\circ}$ grau incompleto & 22 & 14,7 & \\
\hline Superior completo & 5 & 3,3 & \\
\hline Superior incompleto & 12 & 8 & \\
\hline \multicolumn{4}{|l|}{ Estado civil } \\
\hline Casado(a)/mora com companheiro(a) & 74 & 49,3 & \multirow{4}{*}{$<0,001$} \\
\hline Solteiro(a) & 65 & 43,3 & \\
\hline Viúvo(a) & 4 & 2,7 & \\
\hline Separado(a) ou Divorciado(a) & 7 & 4,7 & \\
\hline \multicolumn{4}{|l|}{ Renda familiar } \\
\hline Até um salário mínimo & 92 & 61,3 & \multirow{5}{*}{$<0,001$} \\
\hline Mais de 1 a 2 salários mínimos & 34 & 22,7 & \\
\hline Mais de 2 a 3 salários mínimos & 13 & 8,7 & \\
\hline Mais de 3 a 4 salários mínimos & 8 & 5,3 & \\
\hline Mais de 4 salários mínimos & 3 & 2 & \\
\hline \multicolumn{4}{|l|}{ Trabalha } \\
\hline Sim & 65 & 43,3 & \multirow{2}{*}{0,102} \\
\hline Não & 85 & 56,7 & \\
\hline \multicolumn{4}{|l|}{ Tempo de diagnóstico do HIV } \\
\hline Menos de 1 ano & 13 & 8,7 & \multirow{4}{*}{$<0,001$} \\
\hline De 1 a 5 anos & 72 & 48 & \\
\hline De 5 a 10 anos & 33 & 22 & \\
\hline Mais de 10 anos & 32 & 21,3 & \\
\hline \multicolumn{4}{|l|}{ Tempo de Tratamento com a TARV } \\
\hline Menos de 1 ano & 16 & 10,7 & \multirow{4}{*}{$<0,001$} \\
\hline De 1 a 5 anos & 76 & 51,1 & \\
\hline De 5 a 10 anos & 30 & 20,1 & \\
\hline Mais de 10 anos & 27 & 18,1 & \\
\hline \multicolumn{4}{|l|}{ Realiza atividade física } \\
\hline Sim & 25 & 16,7 & \multirow{2}{*}{$<0,001$} \\
\hline Não & 125 & 83,3 & \\
\hline \multicolumn{4}{|l|}{ Utiliza preservativo nas relações sexuais } \\
\hline Sim & 88 & 58,7 & \multirow{4}{*}{$<0,001$} \\
\hline Não & 20 & 13,3 & \\
\hline Às vezes & 16 & 10,7 & \\
\hline Não possui relação sexual & 26 & 17,3 & \\
\hline
\end{tabular}




\begin{tabular}{|c|c|c|c|}
\hline Via de contaminação pelo HIV & & & \\
\hline Vertical & 2 & 1,3 & \multirow{4}{*}{$<0,001$} \\
\hline Relação sexual & 146 & 97,3 & \\
\hline Acidente com perfurocortantes & 1 & 0,7 & \\
\hline Outros & 1 & 0,7 & \\
\hline \multicolumn{4}{|l|}{ Doença oportunista prévia } \\
\hline Sim & 35 & 23,3 & \multirow{2}{*}{$<0,001$} \\
\hline Não & 115 & 76,7 & \\
\hline \multicolumn{4}{|c|}{ Falta de adesão à TARV no prontuário } \\
\hline Sim & 34 & 22,8 & \multirow{2}{*}{$<0,001$} \\
\hline Não & 115 & 77,2 & \\
\hline
\end{tabular}

${ }^{1}$ p-valor do teste Qui-quadrado para comparação de proporção (se p-valor <0,05, as proporções diferem significativamente).

$\mathrm{Na}$ Tabela 2, foram apresentados as médias e os desvios-padrões dos escores de QV de acordo com os fatores sociodemográficos dos avaliados, segundo os domínios estabelecidos pelo instrumento WHOQOL-HIV-Bref. Verifica-se que, no domínio físico, apenas a variável sexo foi significativa para a $\mathrm{QV}$, sendo o masculino aquele que apresenta a maior média $(M=15,15)$.

Em relação ao domínio psicológico, o teste foi significativo nos itens sexo, faixa etária, renda familiar e possuir trabalho. As maiores médias foram expressas pelo sexo masculino $(M=15,40)$, faixa etária de 40 a 60 anos $(M=14,79)$, renda familiar de três a quatro SM $(M=17,10)$ e vínculo empregatício formal/ informal $(M=14,88)$.

No que concerne à independência, nota-se o fator trabalho como significante para melhorar a QV, pois a maior média foi apresentada pelo grupo que declarou exercer atividades remuneradas $(M=14,88)$. Acerca do domínio das relações sociais, os fatores socioeconômicos que apresentaram significância foram sexo masculino $(M=14,60)$ e renda familiar maior do que três a quatro SM $(M=17,12)$.

Para o domínio ambiente, os fatores que alteraram a QV foram faixa etária, renda familiar e trabalho. Os entrevistados com maior média do escore avaliado foram os com idade de 40 a 60 anos $(M=12,77)$, renda maior de quatro $S M(M=16,83)$ e que possuíam trabalho remunerado $(M=12,82)$. Já no domínio espiritual, apenas os fatores sexo masculino e faixa etária maior do que 60 anos apresentaram significância ( $M=13,73$ e $M=14$, respectivamente).

Tabela 2 - Distribuição da média e desvio-padrão do escore de qualidade de vida conforme domínios do WHOQOL-HIV-Bref, segundo dados sociodemográfico dos avaliados. Recife, PE, Brasil, 2016. (continua)

\begin{tabular}{lcccccc}
\hline Fator avaliado & Físico & Psicológico & Independência & $\begin{array}{c}\text { Relações } \\
\text { sociais }\end{array}$ & Ambiente & Espiritual \\
\hline Sexo & & & & & & \\
Feminino & $13,36 \pm 3,63$ & $13,29 \pm 3,36$ & $13,78 \pm 2,49$ & $12,73 \pm 4,09$ & $11,69 \pm 2,95$ & $11,51 \pm 4,36$ \\
Masculino & $15,15 \pm 3,35$ & $15,40 \pm 2,46$ & $13,81 \pm 2,84$ & $14,60 \pm 3,39$ & $12,47 \pm 2,94$ & $13,73 \pm 3,85$ \\
p-valor & 0,004 & $<0,001$ & 0,556 & 0,007 & 0,066 & 0,003 \\
\hline Faixa etária & & & & & & \\
$18-28$ & $14,34 \pm 3,32$ & $14,51 \pm 2,66$ & $14 \pm 2,09$ & $13,49 \pm 3,68$ & $11,17 \pm 2,90$ & $11,20 \pm 4,04$ \\
$29-39$ & $13,44 \pm 3,56$ & $12,90 \pm 3,44$ & $14,02 \pm 2,34$ & $12,96 \pm 4,08$ & $11,70 \pm 2,52$ & $11,27 \pm 4,24$ \\
$40-60$ & $14,27 \pm 3,89$ & $14,79 \pm 3,11$ & $13,54 \pm 3,01$ & $13,83 \pm 3,91$ & $12,77 \pm 3,18$ & $13,83 \pm 4,16$ \\
$>60^{2}$ & 14 & 12,80 & 8 & 6 & 6,50 & 14 \\
p-valor ${ }^{3}$ & 0,555 & 0,014 & 0,444 & 0,277 & 0,011 & 0,006 \\
\hline
\end{tabular}




\begin{tabular}{|c|c|c|c|c|c|c|}
\hline \multicolumn{7}{|l|}{ Grau de instrução } \\
\hline Nenhum & $9,33 \pm 2,31$ & $12,80 \pm 1,39$ & $11,67 \pm 3,51$ & $11,67 \pm 3,79$ & $9,83 \pm 3,33$ & $12 \pm 5,29$ \\
\hline $1^{\circ}$ grau incompleto & $13,86 \pm 3,49$ & $13,27 \pm 3,16$ & $13,45 \pm 2,91$ & $12,41 \pm 3,76$ & $11,55 \pm 2,60$ & $12,36 \pm 4,52$ \\
\hline $1^{\text {o }}$ grau completo & $13,14 \pm 4,45$ & $13,22 \pm 3,71$ & $13,71 \pm 2,88$ & $13,10 \pm 4,25$ & $10,83 \pm 3,21$ & $11,71 \pm 4,60$ \\
\hline $2^{\circ}$ grau incompleto & $14,09 \pm 3,38$ & $14,69 \pm 3,46$ & $13,73 \pm 2,39$ & $13,14 \pm 3,75$ & $12,64 \pm 2,71$ & $12,32 \pm 4,19$ \\
\hline $2^{\mathrm{o}}$ grau completo & $14,58 \pm 3,43$ & $14,62 \pm 2,75$ & $14,42 \pm 2,31$ & $14,05 \pm 4,24$ & $12,26 \pm 2,97$ & $12,63 \pm 4,15$ \\
\hline Sup. incomp. & $14,42 \pm 3,37$ & $15,27 \pm 3,08$ & $14 \pm 1,71$ & $15,75 \pm 2,26$ & $13,12 \pm 2,42$ & $11,33 \pm 3,47$ \\
\hline Sup. comp. & $14,60 \pm 4,16$ & $13,60 \pm 4,66$ & $12,60 \pm 2,97$ & $13,80 \pm 4,44$ & $13,40 \pm 5,27$ & $13,20 \pm 6,26$ \\
\hline $\mathrm{p}$-valor ${ }^{3}$ & 0,357 & 0,197 & 0,501 & 0,134 & 0,146 & 0,982 \\
\hline \multicolumn{7}{|l|}{ Estado civil } \\
\hline $\begin{array}{l}\text { Casado/ } \\
\text { companheiro }\end{array}$ & $14,23 \pm 3,54$ & $14,14 \pm 3,08$ & $13,85 \pm 2,43$ & $13,74 \pm 4,03$ & $12,02 \pm 2,97$ & $12,31 \pm 4,74$ \\
\hline Solteiro & $13,85 \pm 3,85$ & $14,20 \pm 3,20$ & $13,71 \pm 2,89$ & $13,06 \pm 3,92$ & $11,80 \pm 2,89$ & $12,69 \pm 3,83$ \\
\hline Viúvo & $13,50 \pm 3,11$ & $12,60 \pm 6,14$ & $13,50 \pm 2,08$ & $13,75 \pm 4,65$ & $14,25 \pm 2,60$ & $10,25 \pm 2,50$ \\
\hline Separado & $12,86 \pm 2,91$ & $11,89 \pm 3,01$ & $14 \pm 2,31$ & $12,29 \pm 3,15$ & $11,57 \pm 3,78$ & $9,29 \pm 3,59$ \\
\hline $\mathrm{p}$-valor ${ }^{1}$ & 0,729 & 0,268 & 0,946 & 0,556 & 0,405 & 0,154 \\
\hline \multicolumn{7}{|l|}{ Renda familiar } \\
\hline Até $1 \mathrm{SM}$ & $13,36 \pm 3,78$ & $13,24 \pm 3,15$ & $13,27 \pm 2,95$ & $12,64 \pm 3,90$ & $11,18 \pm 2,86$ & $11,91 \pm 4,35$ \\
\hline 1 a 2 SM & $14,68 \pm 3,27$ & $14,92 \pm 3,32$ & $14,71 \pm 1,82$ & $13,68 \pm 4,15$ & $12,65 \pm 2,40$ & $12 \pm 4,15$ \\
\hline 2 a $3 \mathrm{SM}$ & $15,31 \pm 3,02$ & $14,83 \pm 2,60$ & $14,23 \pm 1,54$ & $14,77 \pm 3,30$ & $12,50 \pm 2,89$ & $12,85 \pm 3,58$ \\
\hline 3 a 4 SM & $15,75 \pm 2,87$ & $17,10 \pm 2,09$ & $14,88 \pm 1,25$ & $17,12 \pm 1,25$ & $15,38 \pm 1,83$ & $15,75 \pm 4,46$ \\
\hline$>4 \mathrm{SM}$ & $14,67 \pm 4,51$ & $16 \pm 0,80$ & $14,33 \pm 1,53$ & $16,67 \pm 0,58$ & $16,83 \pm 2,08$ & $15 \pm 5$ \\
\hline $\mathrm{p}$-valor ${ }^{3}$ & 0,133 & 0,001 & 0,130 & 0,002 & $<0,001$ & 0,156 \\
\hline \multicolumn{7}{|l|}{ Possui Trabalho } \\
\hline Sim & $14,57 \pm 3,27$ & $14,88 \pm 2,74$ & $14,88 \pm 1,63$ & $14,05 \pm 3,86$ & $12,82 \pm 2,73$ & $12,83 \pm 4,18$ \\
\hline Não & $13,53 \pm 3,83$ & $13,36 \pm 3,44$ & $12,95 \pm 2,89$ & $12,87 \pm 3,96$ & $11,31 \pm 2,99$ & $11,86 \pm 4,38$ \\
\hline p-valor ${ }^{1}$ & 0,116 & 0,009 & $<0,001$ & 0,054 & 0,003 & 0,160 \\
\hline
\end{tabular}

${ }^{1} \mathrm{p}$-valor do teste de Mann-Whitney; ${ }^{2} \mathrm{O}$ desvio-padrão não foi calculado no subgrupo de mais de 60 anos, na faixa etária, porque apenas um idoso compôs a amostra do estudo; ${ }^{3} \mathrm{p}$-valor do teste de Kruskal-Wallis.

A Tabela 3 identifica a média do escore de QV segundo os domínios comportamentais de saúde e clínico dos avaliados. No domínio físico, verifica-se que a adesão à TARV no prontuário foi fator mais significativa para alterar a QV (p-valor $=0,028)$, pois o grupo que não possuía registro de falta de adesão à TARV em prontuário apresentou melhor média do escore de QV $(M=14,32)$.

No tocante às relações sociais, não houve significância para nenhum dado avaliado. Já o domínio espiritual revelou que o tempo de diagnóstico de HIV superior a 10 anos e tempo de tratamento medicamentoso também superior a 10 anos foram determinantes para alterar de forma significativa a QV, apresentando as médias 14,12 pontos e 12,63 pontos, respectivamente.

Nos domínios psicológicos e nível de independência, nenhuma variável foi estatisticamente significante para modificar a QV. 
Tabela 3 - Distribuição da média e desvio-padrão do escore de qualidade de vida conforme domínios do WHOQOL-HIV-Bref, segundo dados comportamental de saúde e clínico dos avaliados. Recife, PE, Brasil, 2016

\begin{tabular}{|c|c|c|c|c|c|c|}
\hline Fator avaliado & Físico & Psicológico & Independência & $\begin{array}{c}\text { Relações } \\
\text { sociais }\end{array}$ & Ambiente & Espiritual \\
\hline \multicolumn{7}{|c|}{ Tempo de diagnóstico } \\
\hline$<$ de 1 ano & $14,23 \pm 3,70$ & $15,32 \pm 2,71$ & $14,08 \pm 3,33$ & $14,46 \pm 3,78$ & $10,96 \pm 2,69$ & $12,62 \pm 5,20$ \\
\hline 1 a 5 anos & $13,72 \pm 3,64$ & $13,51 \pm 3,65$ & $13,42 \pm 2,53$ & $12,76 \pm 4,03$ & $11,85 \pm 3,03$ & $11,74 \pm 4,41$ \\
\hline 5 a 10 anos & $13,94 \pm 3,49$ & $14,11 \pm 2,78$ & $14,58 \pm 2,41$ & $13,67 \pm 3,85$ & $12,12 \pm 2,63$ & $11,55 \pm 3,78$ \\
\hline$>$ de 10 anos & $14,50 \pm 3,81$ & $14,55 \pm 2,68$ & $13,69 \pm 2,56$ & $14,03 \pm 3,86$ & $12,47 \pm 3,24$ & $14,12 \pm 3,83$ \\
\hline$p$-valor ${ }^{3}$ & 0,736 & 0,275 & 0,107 & 0,308 & 0,521 & 0,042 \\
\hline \multicolumn{7}{|c|}{ Tempo de tratamento } \\
\hline Menos de 1 ano & $14,12 \pm 4$ & $14,95 \pm 3,38$ & $14,25 \pm 3,15$ & $14 \pm 4,02$ & $11,38 \pm 2,62$ & $11,56 \pm 5,19$ \\
\hline 1 a 5 anos & $13,84 \pm 3,59$ & $13,37 \pm 3,63$ & $13,34 \pm 2,54$ & $12,47 \pm 4,15$ & $11,81 \pm 3,09$ & $11,71 \pm 4,41$ \\
\hline 5 a 10 anos & $13,17 \pm 3,70$ & $14 \pm 2,54$ & $14,27 \pm 2,64$ & $14,03 \pm 3,58$ & $12 \pm 2,63$ & $11,77 \pm 3,62$ \\
\hline Mais de 10 anos & $15,16 \pm 3,34$ & $15,20 \pm 2,09$ & $14,15 \pm 2,32$ & $14,78 \pm 3,30$ & $12,87 \pm 3,02$ & $15,07 \pm 3,10$ \\
\hline p-valor ${ }^{3}$ & 0,174 & 0,053 & 0,116 & 0,056 & 0,427 & 0,003 \\
\hline \multicolumn{7}{|c|}{ Realiza atividade física } \\
\hline Sim & $14,24 \pm 3,52$ & $13,98 \pm 2,95$ & $14,24 \pm 2,22$ & $13,36 \pm 4,02$ & $12,46 \pm 2,44$ & $11,72 \pm 4$ \\
\hline Não & $13,93 \pm 3,66$ & $14,03 \pm 3,30$ & $13,70 \pm 2,67$ & $13,38 \pm 3,95$ & $11,86 \pm 3,05$ & $12,39 \pm 4,38$ \\
\hline p-valor ${ }^{1}$ & 0,759 & 0,773 & 0,410 & 0,968 & 0,258 & 0,484 \\
\hline \multicolumn{7}{|c|}{ Utiliza preservativo } \\
\hline Sim & $14,41 \pm 3,41$ & $14,67 \pm 2,88$ & $13,98 \pm 2,60$ & $14,06 \pm 3,74$ & $11,94 \pm 2,84$ & $12,60 \pm 4,33$ \\
\hline Não & $13,35 \pm 3,82$ & $12,60 \pm 3,32$ & $13,70 \pm 2,25$ & $12,25 \pm 4,58$ & $11,42 \pm 2,48$ & $11,85 \pm 4,53$ \\
\hline Às vezes & $14,19 \pm 4,17$ & $14,35 \pm 3,71$ & $14,38 \pm 2,31$ & $13,69 \pm 4,21$ & $12,81 \pm 3,03$ & $13,31 \pm 4,27$ \\
\hline $\begin{array}{l}\text { Não possui re } \\
\text { sexual }\end{array}$ & $12,88 \pm 3,77$ & $12,71 \pm 3,43$ & $12,85 \pm 2,94$ & $11,77 \pm 3,50$ & $11,92 \pm 3,64$ & $10,88 \pm 3,96$ \\
\hline$p$-valor ${ }^{3}$ & 0,249 & 0,006 & 0,305 & 0,029 & 0,604 & 0,198 \\
\hline \multicolumn{7}{|c|}{ Via de transmissão } \\
\hline Vertical & $12,50 \pm 0,71$ & $14,80 \pm 0,57$ & $14,50 \pm 2,12$ & $15,50 \pm 0,71$ & $12,50 \pm 1,41$ & $15,50 \pm 4,95$ \\
\hline Relação sexual & $14,04 \pm 3,65$ & $14,02 \pm 3,26$ & $13,78 \pm 2,61$ & $13,34 \pm 3,99$ & $12,01 \pm 2,96$ & $12,25 \pm 4,33$ \\
\hline Perfuros ${ }^{2}$ & 10 & 16 & 16 & 14 & 6,50 & 12 \\
\hline Outros $^{2}$ & 12 & 11,20 & 11 & 15 & 10 & 11 \\
\hline p-valor ${ }^{3}$ & 0,506 & 0,648 & 0,480 & 0,902 & 0,338 & 0,781 \\
\hline \multicolumn{7}{|c|}{ Doença Oportunista } \\
\hline $\operatorname{Sim}$ & $14,09 \pm 3,88$ & $13,55 \pm 3,09$ & $13,40 \pm 2,16$ & $13,77 \pm 3,69$ & $12,60 \pm 3,16$ & $13 \pm 4,95$ \\
\hline Não & $14,09 \pm 3,88$ & $14,16 \pm 3,27$ & $13,90 \pm 2,72$ & $13,26 \pm 4,03$ & $11,77 \pm 2,88$ & $12,06 \pm 4,10$ \\
\hline$p$-valor ${ }^{1}$ & 0,839 & 0,274 & 0,077 & 0,608 & 0,192 & 0,287 \\
\hline \multicolumn{7}{|c|}{ Falta de adesão à TARV } \\
\hline Sim & $12,88 \pm 3,49$ & $13,01 \pm 3,88$ & $13,47 \pm 2,57$ & $12,97 \pm 4,08$ & $11,79 \pm 3,04$ & $11,09 \pm 4,20$ \\
\hline Não & $14,32 \pm 3,63$ & $14,29 \pm 2,97$ & $13,86 \pm 2,62$ & $13,49 \pm 3,93$ & $12,05 \pm 2,93$ & $12,68 \pm 4,28$ \\
\hline p-valor ${ }^{1}$ & 0,028 & 0,114 & 0,225 & 0,420 & 0,501 & 0,069 \\
\hline
\end{tabular}

${ }^{1} \mathrm{p}$-valor do teste de Mann-Whitney; ${ }^{2} \mathrm{O}$ desvio-padrão não foi calculado no subgrupo de acidentes perfurocortantes e outros, na via de transmissão, porque apenas um paciente compôs a amostra do estudo, em cada fração referida; ${ }^{3} \mathrm{p}$-valor do teste de Kruskal-Wallis. 


\section{DISCUSSÃO}

Foi observada a prevalência do sexo feminino, pois, embora a literatura ainda apresente destaque para o masculino, as pesquisas recentes e nacionais evidenciam maior representatividade do sexo feminino, o que é consistente com a tendência epidemiológica atual da doença no país, marcada pela feminização, pauperização e aumento na vulnerabilidade da população não jovem ${ }^{(9-10)}$. No entanto, não se pode deixar de mencionar que a transmissão do HIV encontra-se associada, principalmente, aos comportamentos sexuais de risco, como o não uso de preservativo, múltiplos parceiros sexuais, início precoce das relações sexuais e uso de substâncias psicoativas durante a prática sexual| ${ }^{(11)}$.

No aspecto social, os resultados são semelhantes aos divulgados pelo Ministério da Saúde ${ }^{(2)}$. É importante ressaltar que as disparidades econômicas encontradas configuram-se agravantes para piorar a situação de saúde das pessoas, pela associação com as condições de vulnerabilidade frente ao HIV. Assim, tem-se realizado uma busca incessante para a garantia dos direitos à saúde de todos e a mudança do perfil atual da Aids, que evidencia tão nitidamente as injustiças sociais ${ }^{(12)}$.

Com relação às variáveis clínicas, a maior porcentagem encontrada, relacionada à variável tempo de diagnóstico, foi de indivíduos com conhecimento de sua situação sorológica havia menos de 5 anos, dado consonante com estudos recentes ${ }^{(10,13)}$. Pelo apresentado, é imprescindível a participação da equipe multiprofissional nos serviços especializados de atendimento às PVHA para fortalecer a adesão ao tratamento, uma vez que os primeiros anos de acompanhamento são fundamentais para a garantia de fortalecimento do vínculo com os profissionais e para o empoderamento do paciente na corresponsabilização por seu tratamento.

Outra variável que obteve destaque foi o número significativo de pessoas que afirmaram utilizar o preservativo de modo irregular. Nesse sentido, é imperioso reforçar que a atividade sexual sem proteção é fator preponderante para a manutenção da cadeia de transmissão do HIV. Uma investigação, desenvolvida nos Estados Unidos da América, identificou que as principais argumentações dos participantes envolvidos para não utilizar regularmente o preservativo foram a preferência pessoal e o medo de rejeição, apresentando semelhança com o presente estudo(14).

Em mais de 95\% dos entrevistados a transmissão do HIV ocorreu pela relação sexual, ratificando o último boletim epidemiológico de HIV/Aids, segundo o qual em mais de $80 \%$ dos casos registrados, no Brasil, a propagação do vírus deu-se em razão do sexo não seguro ${ }^{(2)}$.

Entre casais soroconcordantes, o uso regular do preservativo é a medida preventiva mais efetiva, pois tem o propósito de evitar reinfecção de cepas resistentes aos medicamentos, aumento da carga viral e transmissão de outras infecções sexualmente transmissíveis (IST). Dessa maneira, as instituições de saúde devem estar organizadas para incluir, no cuidado integral aos seus clientes, os aspectos da vida sexual, com a garantia dos insumos de prevenção e assistência acerca das orientações sobre os aspectos preventivos, visto que a distribuição gratuita do preservativo não elimina as barreiras de cunho cultural, social e emocional que implicam práticas sexuais desprotegidas ${ }^{(15)}$.

Diante dos resultados, foi identificada uma baixa participação dos entrevistados em atividades físicas, o que configura um nível insatisfatório dessa atividade nessa população. O desenvolvimento dessa prática é recomendado para todas as pessoas, pois, além de ser benéfica e segura, possui efeitos positivos nos parâmetros metabólicos, morfológicos, psicológicos e funcionais ${ }^{(16)}$.

No tocante à presença de infecções oportunistas em indivíduos com comprometimento imunológico, é necessário diferir os casos Aids dos assintomático-moderados, pois a presença dessas doenças estão diretamente relacionadas à imunocompetência do paciente ${ }^{(17)}$.

A fim de alcançar melhores resultados terapêuticos e prevenir o desenvolvimento de desfechos desfavoráveis, é imprescindível a boa adesão à TARV. Foi encontrado nesta investigação pouco mais de $22 \%$ de participantes com descrição de falha na adesão em prontuário, no entanto, não foi estabelecido nenhum ponto de corte para a definição da boa adesão, sendo, portanto uma limitação nessa variável. 
O estudo em pauta destaca a relevância das variáveis sociodemográficas para a mensuração da QV. As mulheres apresentaram escores menores em todos os domínios avaliados, o que evidencia maior vulnerabilidade feminina ao comprometimento da QV. Tal vulnerabilidade dá-se, substancialmente, pelas diferenças marcantes nos aspectos culturais, sociais e econômicos, que não conferem oportunidades igualitárias para promoção, proteção e manutenção da saúde, o que justifica, inclusive, a transição socioeconômica da infecção(9).

Quanto à faixa etária, a população que se encontrava entre 40 e 60 anos apresentou melhor escore de QV nos domínios psicológico, relações sociais, ambiente e espiritual, dado que corrobora estudo realizado na Nigéria, onde, ao investigar a relação da QV com a faixa etária, encontrou-se resultado semelhante $^{(18)}$. Em contraponto, uma pesquisa realizada na província chinesa de Zhejiang mostrou que PVHA com menos de 30 anos possuíam melhores escores de QV em todos os seis domínios avaliados ${ }^{(19)}$. Tais dados reafirmam que os efeitos da infecção por HIV podem ser agravados pelo processo da imunossenescência, afetando a QV de pessoas idosas.

Apesar do presente trabalho não ter demonstrado influência estatisticamente significativa entre grau de instrução e aumento de QV, outros estudos, realizados na China, Brasil e Uganda, mostraram que quanto maior o tempo de escolaridade, maior a QV das pessoas, uma vez que o nível de instrução e o acesso às informações sobre HIV/Aids são diretamente proporcionais, o que possibilita às PVHA com mais anos de estudo terem melhores recursos internos e externos para lidarem com a sua condição sorológica $^{(12,19)}$.

As pessoas que referiram estar trabalhando apresentaram melhor média de QV, o que corrobora outros estudos em que esse achado indica que a inclusão de PVHA no ambiente laboral é favorável para o aumento da $Q V^{(9,14)}$.

Quanto ao tempo de tratamento e de ciência da infecção por HIV, identificou-se uma associação com o domínio espiritualidade. A espiritualidade remete ao significado da vida e da razão de viver, e não apenas a crenças e práticas religiosas. Os indivíduos que alcançaram melhores médias no escore desse domínio foram aqueles que tinham 10 anos ou mais de diagnóstico e tratamento, podendo essa conjuntura explicar que com o passar do tempo há um processo de amadurecimento na percepção do viver com $\mathrm{HIV}^{(20)}$.

Aqueles que não tinham registros nos prontuários de falta de adesão à TARV obtiveram melhor média em todos os domínios, e, assim, interferência estatística significativa na saúde física. Sabe-se que a TARV melhora a QV por causar queda na quantificação de cópias do HIV, melhorando a imunidade, reduzindo o surgimento de infecções oportunistas e as resistências virais e, por conseguinte, reduzindo a transmissão do HIV.

Salienta-se que, no processo do cuidar, os profissionais de saúde, em especial o enfermeiro, exercem papel de fundamental importância para uma melhor QV das PVHA. Esse profissional é capaz desenvolver ações de educação em saúde que abrangem a (re)construção dos hábitos que melhoram a QV, além de assistir na integralidade os sujeitos que vivem com uma doença de caráter crônico e estigmatizante como o HIV a partir dos fatores biopsicossociais, orientado, sobretudo, pela sistematização da assistência em enfermagem ${ }^{(21-22)}$.

Sendo assim, faz-se reconhecer os grandes avanços que vem ocorrendo na área do HIV/Aids no Brasil, o que remete à redução da mortalidade por Aids desde a introdução da TARV. Entretanto, o estabelecimento desses avanços não se fez acompanhar de ampliação dos serviços, tampouco de profissionais de saúde qualificados, resultando em um quadro em que os usuários já reclamam da demora para a marcação de consultas, da dificuldade de acesso a exames e tratamentos especializados, o que se reflete negativamente na QV das PVHA.

Por fim, conhecer o perfil sociodemográfico, comportamental de saúde e clínico, bem como os domínios da QV de PVHA, deve contribuir para a realização de um planejamento adequado no que concerne às atividades de políticas públicas direcionadas para o desenvolvimento de ações na área da saúde visando à melhoria da QV de pessoas com o diagnóstico positivo de HIV. 
O estudo apresentou como limitações o delineamento transversal e uma amostra não probabilística, o que não permite estabelecer relações de causa e efeito. Os resultados, no entanto, agregaram novos conhecimentos científicos acerca do comportamento das PVHA, subsidiando o planejamento de ações de promoção da saúde e QV, especialmente da Região Nordeste do país.

\section{CONCLUSÃO}

A QV é um parâmetro para a avaliação dos níveis de saúde de uma população, por isso tem uma noção polissêmica. A infecção por HIV, por ser uma condição crônica, requer um tratamento contínuo, permeado por vários estigmas desde sua origem, e afeta a QV das PVHA em vários aspectos. Neste estudo, evidenciou-se que a forma como os diversos fatores influenciam a QV de PVHA é bastante heterogênea.

Os resultados apresentados neste construto mostram prejuízos na QV de PVHA, com destaque para as variáveis econômicas e sociodemográficas, que foram as que mais influenciaram a mensuração, interferindo em todos os domínios.

Apesar dos avanços na área do HIV, muitos desafios ainda persistem no âmbito social, na prevenção e na assistência. Assim, a compreensão de QV para as PVHA é fundamental, tendo em vista que o diagnóstico positivo de HIV ainda repercute no indivíduo e estende-se para todas as áreas da sua vida, transcendendo o estado físico e atingindo o contexto das relações sociais e sexuais, saúde psicológica e espiritual.

Por fim, espera-se que o estudo possa ter contribuído para a ampliação do conhecimento sobre os aspectos que promovem uma melhor QV aos indivíduos infectados pelo HIV, favorecendo a construção de novas estratégias capazes de amenizar o impacto dessa doença na sociedade, melhorar a adesão medicamentosa e fortalecer as políticas do Programa Nacional de IST/Aids.

\section{REFERÊNCIAS}

1. The Joint United Nations Programme on HIV/AIDS (UNAIDS). Global AIDS UPDATE - 2016. 2016 [acesso em 12 mar 2017]. Disponível: http://www.unaids.org/sites/default/files/media_asset/global-AIDS-update-2016_en.pdf.

2. Ministério da Saúde (BR). Secretaria de Vigilância em Saúde, Departamento de DST, AIDS e Hepatites Virais. Boletim Epidemiológico AIDS e DST. Brasília: Ministério da Saúde; 2016.

3. Vieira ACS, Rocha MSG, Head JF, Casimiro IMAPC. A epidemia de HIV/Aids e a ação do Estado. Diferenças entre Brasil, África do Sul e Moçambique. Rev. katálysis. [Internet] 2014;17(2) [acesso em 13 jul 2017]. Disponível: http:// dx.doi.org/10.1590/S1414-49802014000200005.

4. Herrmann S, McKinnon E, Hyland NB, Lalanne C, Mallal S, Nolan D, Chassany O, et al. HIV-related stigma and physical symptoms have a persistent influence on health-related quality of life in Australians with HIV infection. Health qual. life outcomes. [Internet] 2013;11(56) [acesso em 10 mai 2017]. Disponível: https://doi.org/10.1186/14777525-11-56.

5. Pereira EF, Teixeira CS, dos Santos A. Qualidade de vida: abordagens, conceitos e avaliação. Rev. bras. educ. fís. esporte. [Internet] 2012;26(2) [acesso em 13 jul 2017]. Disponível: http://dx.doi.org/10.1590/S1807-55092012000200007.

6. Hipolito RL, de Oliveira DC. Quality of Life of people living with HIV/AIDS: a cross-sectional study. Online braz. j. nurs. [Internet] 2016;15(suppl) [acesso em 01 jun 2017]. Disponível: http://dx.doi.org/10.17665/1676-4285.20165855.

7. Reychler G, Caty G, Vincent A, Billo S, Yombi JC. Validation of the French Version of the World Health Organization Quality of Life HIV Instrument. PLoS One. [Internet] 2013;8(9) [acesso em 16 abr 2017]. Disponível: https://doi. org/10.1371/journal.pone.0073180. 
8. Oliveira Filho JS, Silva PE, Freitas FFQ, Soares JP, Costa MAG, Oliveira e Silva AC, et al. Qualidade de vida de pessoas vivendo com HIV/AIDS. Rev. Baiana de Enfermagem. [Internet] 2014;28(1) [acesso em 13 jul 2017]. Disponível: https:// portalseer.ufba.br/index.php/enfermagem/article/view/9088.

9. de Souza CC, da Mata LRF, Azevedo C, Gomes CRG, Cruz GECP, Toffano SEM. Interiorização do HIV/Aids no Brasil: um estudo epidemiológico. Revista Brasileira Ciências da Saúde. [Internet] 2013;11(35) [acesso em 13 mai 2017] Disponível: http://seer.uscs.edu.br/index.php/revista_ciencias_saude/article/view/1798/1380.

10. Oliveira e Silva AC, Reis RK, Nogueira JA, Gir E. Quality of life, clinical characteristics and treatment adherence of people living with HIV/AIDS. Rev. Latino-Am.Enfermagem. [Internet] 2014;22(6) [acesso em 16 abr 2017]. Disponível: http://dx.doi.org/10.1590/0104-1169.3534.2508.

11. Pereira TG, de Araújo LF, Negreiros F, Barros Neto RNS. Análise do comportamento sexual de risco à infecção pelo HIV em adultos da população em geral. Psico. [Internet] 2016;47(4) [acesso em 14 fev 2018]. Disponível: http://dx.doi. org/10.15448/1980-8623.2016.4.23703.

12. Passos SMK, Souza LDM. An evaluation of quality of life and its determinants among people living with HIV/AIDS from Southern Brazil. Cad. Saúde Pública. [Internet] 2015;31(4) [acesso em 19 abr 2017]. Disponível: http://dx.doi. org/10.1590/0102-311X00000514.

13. Taquette SR. HIV/Aids among adolescents in Brazil and France: similarities and differences. Saúde Soc. [Internet] 2013;22(2) [acesso em 13 mai 2017]. Disponível: http://dx.doi.org/10.1590/S0104-12902013000200029.

14. Camacho-Gonzalez AF, Wallins A, Toledo L, Murray A, Gaul Z, Sutton MY, et al. Risk Factors for HIV Transmission and Barriers to HIV Disclosure: Metropolitan Atlanta Youth Perspectives. AIDS Patient Care and STDs. [Internet] 2016;30(1) [acesso em 03 jun 2017]. Disponível: http://dx.doi.org/ 10.1089/apc.2015.0163.

15. Reis RK, Melo ES, Gir E. Fatores associados ao uso inconsistente do preservativo entre pessoas vivendo com HIV/Aids. Rev. Bras. Enferm. [Internet] 2016;69(1) [acesso em 22 abr 2017]. Disponível: http://dx.doi.org/10.1590/00347167.2016690106i.

16. de Lima LRA, Teixeira DM, dos Santos ECM, Petroski EL. Contribution of Physical Education in the fields of sport, physical activity, health and education for children and young people living with HIV. Rev. Bras. Cineantropom Desempenho Hum. [Internet] 2016;18(2) [acesso em 22 abr 2017]. Disponível: http://dx.doi.org/10.5007/19800037.2016v18n2p243.

17. Spezia LP, Picarelli MEA, Santos ABR. Avaliação da AIDS e a ocorrência de doenças oportunistas e sexualmente transmissíveis em pacientes infectados pelo HIV residentes na região de Indaiatuba, SP. J. Health Sci. Inst. [Internet] 2015;33(4) [acesso em 22 abr 2017]. Disponível: http://www.unip.br/comunicacao/publicacoes/ics/edicoes/2015/04_ out-dez/V33_n4_2015_p303a308.pdf.

18. Akinboro AO, Akinyemi SO, Olaitan PB, Raji AA, Popoola AA, Awoyemi OR, et al. Quality of life of Nigerians living with human immunodeficiency virus. Pan African Medical Journal. [Internet] 2014;18(234) [acesso em 28 abr 2017]. Disponível: http://dx.doi.org/ 10.11604/pamj.2014.18.234.2816.

19. Liping M, Peng X, Haijiang L, Lahong J, Fan L. Quality of life of people living with HIV/AIDS: A cross sectional study in Zhejiang province, China. PLoS One. [Internet] 2015;10(8) [acesso em 02 jun 2017]. Disponível: http://dx.doi.org/ 10.1371/journal.pone.0135705.

20. da Silva JB, da Silva LB. Relação entre religião, espiritualidade e sentido da vida. Revista logos \& existência. [Internet] 2014;3(2) [acesso em 30 mai 2017]. Disponível: http://periodicos.ufpb.br/ojs/index.php/le/article/view/22107/12148.

21. dos Santos El, da Silva AL, Santana PPC, Teixeira PA. Evidências científicas brasileiras sobre adesão à terapia antirretroviral por pessoas que vivem com HIV/AIDS. Revista Eletrônica Gestão \& Saúde. [Internet] 2016;7(1) [acesso em 02 jul 2017]. Disponível: http://dx.doi.org/10.18673/gs.v7i1.22092.

22. Padoin SMM, Zuge SS, dos Santos EEP, Primeira MR, Aldrighi JD, de Paula CC. Adesão à terapia antirretroviral para HIV/Aids. Cogitare Enferm. [Internet] 2013;18(3) [acesso em 02 ago 2017]. Disponível: http://dx.doi.org/10.5380/ ce.v18i3.33553 . 